\title{
Effect of illness expression and liability on familial associations of clinical and subclinical psychosis phenotypes
}

Citation for published version (APA):

Lataster, T., Verweij, K., \& Viechtbauer, W. (2014). Effect of illness expression and liability on familial associations of clinical and subclinical psychosis phenotypes. Acta Psychiatrica Scandinavica, 129(1), 4453. https://doi.org/10.1111/acps.12102

Document status and date:

Published: 01/01/2014

DOI:

10.1111/acps.12102

Document Version:

Publisher's PDF, also known as Version of record

Document license:

Taverne

Please check the document version of this publication:

- A submitted manuscript is the version of the article upon submission and before peer-review. There can be important differences between the submitted version and the official published version of record.

People interested in the research are advised to contact the author for the final version of the publication, or visit the DOI to the publisher's website.

- The final author version and the galley proof are versions of the publication after peer review.

- The final published version features the final layout of the paper including the volume, issue and page numbers.

Link to publication

\footnotetext{
General rights rights.

- You may freely distribute the URL identifying the publication in the public portal. please follow below link for the End User Agreement:

www.umlib.nl/taverne-license

Take down policy

If you believe that this document breaches copyright please contact us at:

repository@maastrichtuniversity.nl

providing details and we will investigate your claim.
}

Copyright and moral rights for the publications made accessible in the public portal are retained by the authors and/or other copyright owners and it is a condition of accessing publications that users recognise and abide by the legal requirements associated with these

- Users may download and print one copy of any publication from the public portal for the purpose of private study or research.

- You may not further distribute the material or use it for any profit-making activity or commercial gain

If the publication is distributed under the terms of Article $25 \mathrm{fa}$ of the Dutch Copyright Act, indicated by the "Taverne" license above, 


\section{Effect of illness expression and liability on familial associations of clinical and subclinical psychosis phenotypes}

Lataster T, Verweij K, Viechtbauer W, GROUP. Effect of illness expression and liability on familial associations of clinical and subclinical psychosis phenotypes.

Objective: Given the familial influences on schizophrenia, it may be hypothesized that specific symptom domains also cluster within families, and that this applies to both clinical and subclinical levels of expression. This hypothesis was put to the test in a group of patients with a DSM-IV diagnosis of psychotic disorder together with their unaffected siblings, and a group of healthy sib-pairs.

Method: Subclinical positive, negative and depressive symptoms in relatives and healthy controls were assessed with the Community Assessment of Psychic Experiences (CAPE). Positive and negative schizotypy in relatives and controls was measured with the Structured Interview for Schizotypy-Revised. Multilevel linear regression analyses were conducted to investigate clustering of symptom dimensions within patient-relative sib-pairs ( $N=811$ pairs), healthy sib-pairs of affected families ( $N=136$ pairs) and healthy control sib-pairs ( $N=58$ pairs).

Results: Familial clustering of symptoms was found in all three groups. Effect sizes were largest in healthy control sib-pairs, smallest in patientrelative sib-pairs and intermediate in healthy sib-pairs of affected families.

Conclusion: Studies of sibling associations in genetic studies of psychometric expression of psychosis liability need to take into account the fact that the higher levels of background genetic risk and presence of diagnosed illness are inversely associated with sibling associations.

\section{T. Lataster,", K. Verweij ${ }^{2, *}$, W. Viechtbauer ${ }^{1}$, GROUP** \\ ${ }^{1}$ South Limburg Mental Health Research and Teaching Network, Maastricht University Medical Centre, Maastricht, ${ }^{2}$ Department of Psychiatry, Rudolf Magnus Institute of Neuroscience, University Medical Center Utrecht, Utrecht, and ${ }^{3}$ Academic Medical Center, University of Amsterdam, Department of Psychiatry, Amsterdam, and ${ }^{4}$ University Medical Center Groningen Department of Psychiatry, University of Groningen, the Netherlands \\ Key words: schizophrenia; family studies; genetic epidemiology; psychopathology}

Tineke Lataster, Department of Psychiatry and Neuropsychology, School for Mental Health and Neuroscience, Maastricht University Medical Centre, PO B0X 616, Maastricht, $6200 \mathrm{MD}$, the Netherlands. E-mail: t.lataster@maastrichtuniversity.nl

*These authors contributed equally to this work.

**GROUP authors are: René S. Kahn², Don H. Linszen ${ }^{3}$, Jim van $0 s^{1}$, Durk Wiersma ${ }^{4}$, Richard Bruggeman ${ }^{4}$, Wiepke Cahn' ${ }^{2}$, Lieuwe de Haan ${ }^{3}$, Lydia Krabbendam? Inez Myin-Germeys ${ }^{1}$

Accepted for publication January 22, 2013

\section{Significant outcomes}

- The results suggest that heritability and familial clustering is decreased in the presence of disease expression and underlying disease liability.

- Disease- and liability-related effects play an important role when investigating familial associations between different symptom dimensions in affected families.

- Molecular genetic studies using sibling discordance as outcome should control for the presence of disease and disease liability.

\section{Limitations}

- Selection bias towards inclusion of those healthy siblings in affected families with the lowest (or highest) level of expression of schizotypy may have occurred.

- Some siblings of schizophrenia patients could have used a defensive method of answering, which may have lowered associations in healthy sib-pairs of affected families. 


\section{Introduction}

The diagnosis of schizophrenia clusters within families (1), and first-degree relatives of patients show an increased prevalence of schizotypal personality disorder $(2,3)$. Familial clustering at the level of diagnostic constructs (4) has been followed up by finer grained analyses examining familial continuity between subclinical dimensions of schizotypy and clinical dimensions of psychotic disorder $(5,6)$. These studies, analysing associations between symptom dimensions or clinical diagnosis in patients, and corresponding schizotypal traits in first-degree relatives, generally have yielded small to moderate familial associations (6-8).

However, this type of patient-relative association may be difficult to interpret, as it may be attenuated by disease-specific environmental (e.g. medication use in patients) or genetic (e.g. risk genes that are present in the patient, but not in the unaffected relative) factors (9). It is therefore important to additionally investigate and compare cross-sibling (subclinical) psychopathological associations in i) healthy unaffected sib-pairs who have a further sibling with a diagnosis of psychotic disorder and ii) sib-pairs from families without an affected first-degree relative. Although several psychopathological dimensions have been investigated across schizotypy and psychotic disorder phenotypes (10-14), the positive and negative symptom dimensions are the domains that are most consistently replicated across latent variable approaches.

We are aware of only a single study investigating cross-sibling associations of symptom dimensions in patients and their healthy relatives and comparing these familial associations to those found in healthy control sib-pairs. The authors report that familial associations for negative symptoms were greater in healthy control sib-pairs than in pairs consisting of a schizophrenia patient and his unaffected sibling (15). These findings suggest that negative symptoms may represent only a weak indicator of genetic risk for the disorder and/or that cross-sibling associations may be confounded by disease-specific environmental factors like antipsychotic medication use in the patients.

In the current study, an attempt was made to control for possible disease-related confounding and the focus was on the arguably more homogenous symptom dimensions rather than the heterogeneous schizophrenia disease construct. To this end, three different groups were investigated with both self-report and interview-based questionnaires, collected as part of a large multisite study on Genetic Risk and Outcome in Psychosis (GROUP).
Aims of the study

To investigate familial clustering of the positive, negative and depressive symptom dimensions in three groups: i) patients with psychotic disorder and their healthy siblings, ii) healthy sib-pairs of Affected Families (hereafter, "healthy sib-pairs OAF") and iii) healthy control sib-pairs. It was hypothesized that familial clustering would be strongest in healthy control sib-pairs and healthy sib-pairs of affected families, as these groups suffer the least illness-related confounding.

\section{Material and methods}

Sample

Data were derived from the baseline measures of an ongoing longitudinal study [Genetic Risk and Outcome in Psychosis (GROUP)] in Europe. Patients were recruited from clinics/clinician referrals in selected representative geographical areas in the Netherlands and in Belgium. Persons identified as potentially eligible were given detailed explanation of the study procedures and were asked informed consent for detailed assessment and for contacting their first-degree family members (brothers, sisters, parents). Healthy controls were selected through a system of random mailings to addresses in the catchment areas of the patients (16).

The full GROUP sample (data release 2.0) consisted of 1100 patients, 1057 healthy siblings of these patients, 919 parents of these patients, 19 parents of patients who were also diagnosed with psychotic disorder, 562 healthy controls and 27 parents of these healthy controls. The current analyses included the i) patients with psychotic disorder and their healthy siblings (hereafter: patient sib-pairs), ii) healthy sib-pairs OAF (two healthy brother(s) and/or sister(s) of the patients included in the study) and iii) healthy control sib-pairs.

Patients were included in the GROUP sample if they had a diagnosis of psychotic disorder in the schizophrenia spectrum (DSM-IV-TR code 295.x) or other psychotic disorder (DSM-IV-TR code 297/298). Another inclusion criterion, for patients, siblings and controls was good command of the Dutch language. Diagnosis in the three groups was based on DSM-IV-TR (17) criteria assessed with the Comprehensive Assessment of Symptoms and History interview (18) or Schedules for Clinical Assessment for Neuropsychiatry version 2.1 (19). 


\section{Lataster et al.}

\section{Ethical issues}

The standing Ethical Review Board approved the study protocol. After full verbal and written information about the study, written informed consent was obtained from all participants before the start of the first assessment. Confidentiality of data was maintained using a unique research ID for each respondent, which enables identification of individuals without the use of names or other identifiers.

Assessment of (sub)-clinical psychotic experiences in the whole sample

Self-reported (subclinical) psychotic experiences in the affective and non-affective domains were assessed with the previously validated Community Assessment of Psychic Experiences (CAPE) (20, 21) (http://www.cape42.homestead.com/). The CAPE is based on the Peters et al. Delusions Inventory (22), modified to also include hallucinatory experiences. For the current analyses, mean scores on frequency of positive, negative and depressive symptoms were used (allowing a maximum of $30 \%$ missing values per subscale).

Interview-based scores on positive and negative subclinical psychotic symptoms were measured in the non-patients with the Structured Interview for Schizotypy-Revised (SIS-R) (23). A mean score on the following items was entered in the analyses as 'positive schizotypy' (30\% maximum partially missing data allowed): referential thinking ('being watched' and 'remarks'), suspiciousness, magical ideation, illusions, psychotic phenomena and derealization/depersonalization. A 'negative schizotypy' variable was calculated by taking the mean score on the items social isolation, introversion, sensitivity, restricted affect, disturbances in associative and goal-directed thinking, poverty of speech and eccentric behaviour (with a maximum of $30 \%$ missing data, conform previous analyses in this sample: (24)).

Analyses

Multilevel linear regression analyses using the XTREG command in STATA 11.2 (25) (taking clustering at the family level into account) were conducted to test the difference in mean scores on the CAPE and SIS-R subscales in the three groups of patient-relative sib-pairs, healthy sib-pairs OAF and healthy control sib-pairs.

\section{Familial clustering of the CAPE in patient-relative sib-pairs}

Multilevel linear regression analyses were conducted to test the association between CAPE positive, negative and depressive subscale scores in the patients (hereafter CAPEpos_pat, CAPEneg_pat and CAPEdep_pat respectively), and CAPE subscale scores in the healthy siblings of these patients (variable names: CAPEpos sib, CAPEneg sib, CAPEdep_sib). Within-symptom dimension associations were tested in three different models: CAPEpos_sib $=$ B0 + B1 CAPEpos_pat + Error; CAPEneg_sib $=\mathrm{B} 0+\mathrm{B} 1$ CAPEneg_pat + Error; CAPEdep_sib $=$ B0 + B1 CAPEdep_pat + Error. In addition, cross-symptom dimension associations were tested, such as CAPEpos sib $=\mathrm{B} 0+\mathrm{B} 1$ CAPEneg_pat + Error and CĀPEpos_sib $=\mathrm{B} 0+\mathrm{B} 1$ CAPEdep_pat + Error. All analyses in patient-relative sib-pairs were a priori controlled for gender, age, education level, ethnicity, illness duration in the patient and clustering at the family level. Only families who contributed at least one patient and one sibling were used for these analyses. To avoid duplication of redundant data, a single patient was chosen at random from families with multiple patients.

Familial clustering of the CAPE and SIS-R in healthy sib-pairs OAF and healthy control sib-pairs

Linear regression analyses were conducted in healthy sib-pairs OAF and healthy control sibpairs to test the between-sibling associations on the different subscales of the CAPE and SIS-R (regression model: CAPE/SIS-Rsubscale_proband $=\mathrm{B} 0+\mathrm{B} 1 \quad$ CAPE/SIS-R subscale_co-sibling + Error). Only families that contributed at least two unaffected siblings of patients with a non-affective psychotic disorder were used. To avoid duplication of redundant data, a single sibling pair was chosen at random from families with more than two siblings. Assignment of siblings as proband and co-sibling was also at random. Data for these analyses were in the wide format with one observation per family (i.e. CAPE/SIS-R scores in the proband and co-sibling presented on the same row in the dataset), and were therefore analysed with the REGRESS command without controlling for clustering at the family level. Again, both within- and cross-symptom dimension associations were tested, a priori controlled for gender, age, education level and ethnicity in the co-sibling. The same approach was used for healthy control sib-pairs. 
Within-subject associations on subscales of the CAPE and SIS-R in siblings and controls

In addition to familial associations, within-subject associations were tested in healthy siblings of affected families and in healthy control sib-pairs across different symptom dimensions in separate multilevel linear regression models taking the family level of clustering into account (e.g. CAPE/ SIS-Rpos_sib1 $=$ B0 + B1 CAPE/SIS-Rneg_sib1 + Error).

\section{Results}

\section{Descriptives}

The total GROUP sample (release 2.0) comprised 491 healthy control families who contributed a total of 562 healthy control participants, and 1066 affected families who contributed 1100 patients with a non-affective psychotic disorder, and 1057 healthy siblings of these patients. Affected families contributed a single patient (209 families, 209 subjects), a single sibling (6 families, 6 subjects), a patient and a sibling (643 families, 1286 subjects), 2 patients ( 23 families, 46 subjects), 1 patient and 2 siblings (132 families, 396 subjects), 2 patients and 1 sibling (6 families, 18 subjects), 3 patients ( 2 families, 6 subjects), 1 patient and 3 siblings ( 30 families, 120 subjects), 2 patients and 2 siblings (5 families, 20 subjects), 3 patients and 1 sibling (1 family, 4 subjects), 1 patient and 4 siblings ( 8 families, 40 subjects) and 1 patient and 5 siblings (1 family, 6 subjects). Control families contributed a single healthy control participant (425 families, 425 subjects), a control sib-pair (61 families, 122 subjects) and a control sib-trio (5 families, 15 subjects).

\section{Subsamples for familial analyses}

For the patient-sib-pair analyses, the following families and participants were excluded: i) families contributing a single patient (209 families, 209 subjects), ii) families contributing two patients but no siblings (23 families, 46 subjects), iii) contributing three patients but no siblings ( 2 families, 6 subjects) and iv) families contributing a single sibling (6 families, 6 subjects). Furthermore, for those families contributing more than one patient, one patient was randomly selected for the analyses (13 patients were randomly excluded). All participants who had missing data on either one of the dependent, independent or confounding variables were also excluded for these analyses, leaving a total of
811 pairs, contributing 641 patients and 811 healthy siblings of these patients.

For the analyses of healthy sib-pairs OAF, only those families contributing at least two healthy siblings OAF were included, and again participants with missing data on the relevant variables were excluded, leaving data of 272 healthy sibs OAF for the analyses (136 pairs). For the analyses of healthy control sib-pairs, after similar selection as in the healthy sib-pairs OAF, data of 116 healthy control sibs (58 healthy control sib-pairs) remained.

Descriptive statistics for the different analyses are depicted in Table 1, and the mean scores on dependent and independent variables in Table 2. Patients and relatives differed significantly on all three dimensions of the CAPE. In the comparison between relatives and controls, a significant difference was apparent for the negative schizotypy subscale of the SIS-R (Table 2).

Familial clustering of the CAPE in patient-relative sib-pairs

The multilevel linear regression analyses testing the CAPE within-symptom dimension association across patients and their healthy siblings revealed small but significant associations (Table 3, diagonal cells). Similarly, small but significant familial associations were found in the CAPE cross-symptom dimension analyses (Table 3 ).

Familial clustering of the CAPE and SIS-R in healthy sib-pairs OAF and healthy control sib-pairs

In healthy sib-pairs OAF, significant within-symptom associations were apparent for the positive, and negative dimension of the CAPE and for the positive schizotypy subscale of the SIS-R (left side of Table 4, between-person effect sizes). Crosssymptom associations were significant only for CAPE positive symptoms in sib 1 and CAPE negative symptoms in sib 2; and for CAPE negative symptoms in sib 1 and CAPE depressive symptoms in sib 2 (left side of Table 4). Effect sizes were in the low range for these analyses.

In healthy control sib-pairs, all within-symptom dimension associations for CAPE and SIS-R were significant (right side of Table 4, between-person effect sizes). Significant cross-symptom associations were found for CAPE and SIS-R, with the exception of the association between the positive symptom dimension of the CAPE in sib 1 and the negative symptom dimension of the CAPE in sib 2 (right side of Table 4). Effect sizes for these analyses were in the moderate range. 


\section{Lataster et al.}

Table 1. Demographic and clinical characteristics

\begin{tabular}{|c|c|c|c|c|}
\hline & Patients ( $N=641)$ & Siblings $(N=811) \dagger$ & Siblings $(N=272)+$ & Controls $(N=116)$ \\
\hline Age (years) & $\begin{array}{l}M=27.5(S D=7.5) \\
\text { range } 15-57\end{array}$ & $\begin{array}{l}M=28.1(S D=8.5) \\
\text { range } 14-60\end{array}$ & $\begin{array}{l}M=28.3(S D=8.3) \\
\text { range } 15-60\end{array}$ & $\begin{array}{l}M=27.6(S D=9.6) \\
\text { range } 16-56\end{array}$ \\
\hline Gender & Male: 490, Female: 151 & Male: 372, Female: 439 & Male: 117, Female: 155 & Male: 44, Female: 72 \\
\hline \multicolumn{5}{|l|}{ Ethnicity } \\
\hline Caucasian & 523 & 685 & 244 & 106 \\
\hline Other & 116 & 125 & 28 & 10 \\
\hline \multicolumn{5}{|l|}{$\begin{array}{l}\text { Education level } \\
\text { (highest degree) }\end{array}$} \\
\hline No education & 4 & 1 & 1 & - \\
\hline Primary school & 75 & 55 & 12 & 1 \\
\hline Secondary school & 207 & 166 & 42 & 23 \\
\hline High school & 168 & 158 & 55 & 35 \\
\hline Vocational education & 162 & 329 & 121 & 51 \\
\hline Unknown & - & 4 & 1 & - \\
\hline Average I0 & $\begin{array}{l}M=96.4(S D=15.1) \\
\text { range } 70-146\end{array}$ & $\begin{array}{l}M=103.4(S D=15.4), \\
\text { range } 70-144\end{array}$ & $\begin{array}{l}M=105.7(S D=15.3) \\
\text { range } 70-140\end{array}$ & $\begin{array}{l}M=110.7(S D=13.3), \\
\text { range } 84-144\end{array}$ \\
\hline $\begin{array}{l}\text { Cannabis-abuse } \\
\text { /dependence }\end{array}$ & $N=273(42.6 \%)$ & $N=111(13.7 \%)$ & $N=36(13.2 \%)$ & $11(9.5 \%)$ \\
\hline \multicolumn{5}{|l|}{ DSM-IV diagnosis } \\
\hline Schizophrenia & 443 & - & - & - \\
\hline Other psychotic disorder & 195 & - & - & - \\
\hline Bipolar disorder & 3 & 5 & 1 & - \\
\hline Depression & - & 86 & 32 & 9 \\
\hline $\begin{array}{l}\text { Schizotypal personality } \\
\text { disorder }\end{array}$ & - & 1 & 1 & \\
\hline $\begin{array}{l}\text { Other non-psychotic } \\
\text { disorder }\end{array}$ & - & 13 & 3 & 1 \\
\hline Postponed diagnosis & - & 2 & 1 & - \\
\hline No diagnosis & - & 704 & 234 & 106 \\
\hline $\begin{array}{l}\text { Illness duration } \\
\text { in years }\end{array}$ & $M=4.6(S D=4.1)$, range $.02-41.1$ & & & \\
\hline
\end{tabular}

$\dagger$ Siblings for the patient-sib analyses.

\$Siblings for the sib-sib analyses (only those families where a minimum of two healthy sibs participated were included for these analyses).

\begin{tabular}{|c|c|c|c|c|}
\hline & Mean (SD) & $\begin{array}{l}\text { Patients vs. controls } \\
\qquad \text {-value }^{*}\end{array}$ & $\begin{array}{l}\text { Relatives vs. controls } \\
\qquad \text {-value }^{*}\end{array}$ & $\begin{array}{c}\text { Patients vs. relatives } \\
\qquad \text {-value }^{*}\end{array}$ \\
\hline \multicolumn{5}{|c|}{ CAPE positive symptoms } \\
\hline Patients & $0.70(0.51)$ & \multirow[t]{3}{*}{0.000} & \multirow[t]{3}{*}{0.760} & \multirow[t]{3}{*}{0.000} \\
\hline Relatives & $0.20(0.20)$ & & & \\
\hline Controls & $0.19(0.18)$ & & & \\
\hline \multicolumn{5}{|c|}{ CAPE negative symptoms } \\
\hline Patients & $1.06(0.55)$ & \multirow[t]{3}{*}{0.000} & \multirow[t]{3}{*}{0.158} & \multirow[t]{3}{*}{0.000} \\
\hline Relatives & $0.55(0.38)$ & & & \\
\hline Controls & $0.48(0.33)$ & & & \\
\hline \multicolumn{5}{|c|}{ CAPE depressive symptoms } \\
\hline Patients & $1.04(0.59)$ & \multirow[t]{3}{*}{0.000} & \multirow[t]{3}{*}{0.056} & \multirow[t]{3}{*}{0.000} \\
\hline Relatives & $0.63(0.40)$ & & & \\
\hline Controls & $0.55(0.34)$ & & & \\
\hline \multicolumn{5}{|c|}{ SIS-R positive schizotypy } \\
\hline Relatives & $0.39(0.41)$ & \multirow[t]{2}{*}{-} & \multirow[t]{2}{*}{0.127} & \multirow[t]{2}{*}{-} \\
\hline Controls & $0.46(0.44)$ & & & \\
\hline \multicolumn{5}{|c|}{ SIS-R negative schizotypy } \\
\hline Relatives & $0.28(0.26)$ & \multirow[t]{2}{*}{-} & \multirow[t]{2}{*}{0.019} & \multirow[t]{2}{*}{-} \\
\hline Controls & $0.34(0.26)$ & & & \\
\hline
\end{tabular}

Table 2. Comparison of means for the three groups on CAPE and SIS-R subscales in patients $(N=641)$, healthy siblings of affected families $(N=811)$ and controls $(N=116)$

${ }^{*} P$-values corresponding to the multilevel linear regression analyses testing the difference in mean scores on the different subscales of the CAPE (Community Assessment of Psychic Experiences) and SIS-R (Structured Interview for Schizotypy-Revised) between the three groups, while controlling for age, gender, education, ethnicity and clustering at the family level. 
CAPE siblings

Positive symptoms

Negative symptoms

Depressive symptoms
$0.12^{* *}$

$0.12^{* *}$

$0.10^{* *}$
$0.13^{* * *}$
$0.16^{* * *}$
$0.12^{* *}$

$0.14^{* * *}$

$0.16^{* * * *}$

$0.10^{* *}$

$\beta$, standardized regression coefficient representing the magnitude of the association between the different subscale scores of the CAPE (Community Assessment of Psychic Experiences).

${ }^{* *} P<0.01$

${ }^{* * *} P<0.001$

Within-subject associations on subscales of the CAPE and SIS-R in siblings and controls

All within-subject associations were significant, with effect sizes in the moderate range [also shown in Table 4 under ' $\beta(w)^{\prime}$ ]'.

A series of multilevel linear regression analyses aimed at testing whether the familial associations were significantly smaller in the patient-relative sib-pairs compared with the healthy control sib-pairs showed significantly larger withinsymptom-dimension familial associations in the healthy control sib-pair group relative to the patient-relative sib-pair group (left side of Table 5). The linear regression analyses testing whether the familial associations were significantly smaller in healthy sib-pairs OAF compared with healthy control sib-pairs showed no significant differences (right side of Table 5).

\section{Discussion}

Main findings

In this study, familial clustering of positive, negative and depressive symptom dimensions was examined in patient-relative sib-pairs, in healthy sib-pairs OAF and in healthy control sib-pairs. Given the inclusion of these three different groups, an attempt was made to elucidate possible diseaserelated factors. Interestingly, associations grew weaker with more evidence of vulnerability for psychotic disorder as the strongest associations were found in healthy control sib-pairs, the weakest in patient-relative sib-pairs and intermediate strength associations in sib-pairs of affected families.

\section{Evidence for shared aetiology?}

Overall, the associations between symptom dimensions were small in patient-relative sib-pairs. This is consistent with evidence from previous research where small associations were revealed $(7,8,15)$. In addition, no specific pattern of clustering was found for positive, negative and depressive symptoms in patient-relative sib-pairs. This finding is inconsistent with one previous study where positive and negative symptoms in the patients predicted corresponding schizotypal symptoms in non-psychotic relatives (6). However, even Fanous and colleagues (6) found a number of cross-symptom dimension associations in addition to the within-symptom dimension associations. These findings suggest that familial factors contribute to the vulnerability to develop psychotic symptoms in general, rather than directly influencing which specific symptoms arise. Moreover, small familial associations in patient-relative sib-pairs and healthy sib-pairs OAF compared with moderate familial associations in healthy control sib-pairs demonstrate the influence of disease and disease vulnerability. The low familial associations in the sib-pairs OAF were not merely the result of overall low scores in this group, as their scores on all three CAPE dimensions did not significantly differ from the CAPE scores of healthy control sib-pairs.

\section{Familial clustering and influence of disease-specific factors}

Disease-related genetic or environmental influences may explain why symptom scores are less strongly associated in patient-relative sib-pairs. Results correspond with a previous study, in which the heritability was calculated for working memory, executive functioning and episodic memory; higher estimates were found in control sibling pairs compared with patient-sibling pairs (9). Similarly, significant positive associations for negative symptoms were found in control sibling pairs but not in patient-sibling pairs (15). These results suggest that heritability and familial clustering is decreased in the presence of the disease and liability to disease. This could be explained in several ways. Psychotic symptoms in the 
Lataster et al.

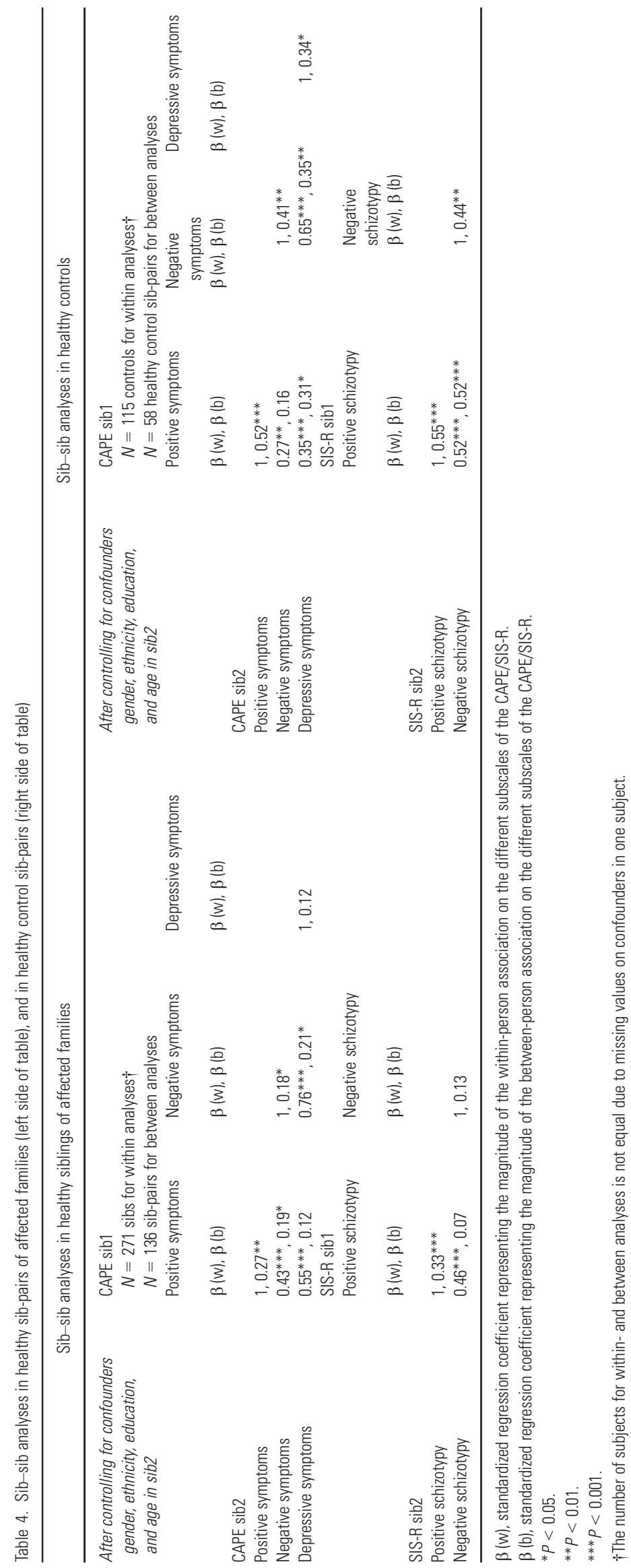


Table 5. Regression analyses testing whether the familial associations were significantly smaller in patient-relative sib-pairs and healthy sib-pairs OAF compared with healthy control sib-pairs

\begin{tabular}{llllll}
\hline SIB 1 & SIB 2 & $\begin{array}{c}\text { Patient-relative sib-pairs vs. } \\
\text { healthy control sib-pairs }\end{array}$ & \multicolumn{2}{l}{$\begin{array}{l}\text { Healthy sib-pairs OAF vs. } \\
\text { healthy control sib-pairs }\end{array}$} \\
\hline CAPE & & $\beta \dagger$ & $95 \%$ Cl & $\beta *$ & $95 \% \mathrm{Cl}$ \\
Capepos & Capepos & -0.41 & -0.67 to $-0.15^{* *}$ & -0.25 & -0.54 to $0.03^{\wedge}$ \\
Capepos & Capeneg & 0.01 & -0.26 to 0.27 & 0.06 & -0.25 to 0.37 \\
Capepos & Capedep & -0.21 & -0.47 to 0.06 & -0.18 & -0.49 to 0.13 \\
Capeneg & Capeneg & -0.26 & -0.53 to $-0.0003^{*}$ & -0.24 & -0.54 to 0.07 \\
Capeneg & Capedep & -0.21 & -0.48 to 0.05 & -0.13 & -0.43 to 0.18 \\
Capedep & Capedep & -0.18 & -0.45 to 0.08 & -0.17 & -0.48 to 0.14 \\
SIS-R & & & & -0.24 & -0.53 to 0.05 \\
SIS-Rpos & SIS-Rpos & & & -0.20 & -0.51 to 0.10 \\
SIS-Rpos & SIS-Rneg & & & -0.30 & -0.61 to $0.01^{\wedge \wedge}$ \\
SIS-Rneg & SIS-Rneg & & & &
\end{tabular}

Capepos, positive symptom score on the CAPE (Community Assessment of Psychic Experiences); Capeneg, negative symptom score on the CAPE; Capedep, depressive symptom score on the CAPE; SIS-Rpos, positive schizotypy measured with the SIS$\mathrm{R}$ (Structured Interview for Schizotypy-Revised); SIS-Rneg, negative schizotypy; $\beta$, standardized regression coefficient representing the between group difference in the familial association between the different subscale scores of the CAPE/SIS-R; $\mathrm{Cl}$, Confidence Interval.

$\wedge P=0.09$.

$\wedge \wedge P=0.06$

${ }^{*} P=0.05$

${ }^{* *} P<0.01$

†Multilevel analyses controlled for clustering at the family level, and for gender, education, ethnicity and age in sib 1.

$\$$ Analyses controlled for gender, education, ethnicity and age in sib1.

patients may arise under the influence of unique environmental factors (for a review see: (26)) such as childhood trauma (27-29) and cannabis use $(30,31)$. In addition, epigenetic changes as a result of such environmental risk factors, and disease-specific de novo mutations may contribute to the development of symptoms in patients (3234). Alternatively, it could be hypothesized that protective factors prevent the unaffected sibling from developing schizophrenia. That is, the healthy sibling may have protective variants of schizophrenia-related genes or may have been exposed to environmental factors that protect against expression of illness given the presence of vulnerability. This is illustrated by findings from an explorative study by Glatt and colleagues who found changes in some genes in peripheral blood in non-psychotic siblings but not in their affected siblings nor in healthy comparison subjects (35).

Thus, disease-related factors in the patient and protective factors in the unaffected sibling may contribute to small familial associations in the patient-relative sib-pairs. At the same time, the absence of these disease-related factors in healthy controls may explain why familial associations were greater for these pairs. Consequently, it could be hypothesized that familial associations are also greater in patient-patient sib-pairs as they share disease-specific influences such as medication use. Hence, a previous study has shown within-symptom associations in patient-patient sib-pairs (36). Unfortunately, in the GROUP sample, only 37 patient-patient sib-pairs were included. Because of missing data on the CAPE in some, and missing values on some of the illness-related confounders, only 22 pairs remained for the cross-sibling analyses. Explorative post hoc analysis of this small sample did not suggest large associations (none of them were significant, with a mean effect size of -0.08 for positive symptoms, 0.01 for negative symptoms and -0.23 for depressive symptoms).

\section{Strengths and weaknesses}

One of the strengths of this study is the inclusion of healthy control sib-pairs. These controls are not influenced by genetic or environmental diseaserelated factors. Owing to the inclusion of these controls, it was possible to measure familial clustering in a healthy population and a comparison could be made with healthy siblings from schizophrenia patients.

Another strength of the current study is the inclusion of healthy sib-pairs OAF, which, to the best of our knowledge, is the first to include such sib-pairs. Investigating these unaffected pairs with genetic vulnerability for the illness allows for the exploration of symptom associations without treatment-specific influences such as medication use. Nevertheless, these unaffected sib-pairs formed part of a family where at least one person developed schizophrenia and therefore diseaserelated factors are still of influence, which likely contributes to the relatively small sib-sib familial associations.

A possible limitation may be that of the healthy siblings in affected families who took part in the study, those with the lowest level of expression of schizotypy participated, whereas those with higher levels did not, or vice versa. The former selection could have contributed to the small number of associations observed between patients and siblings.

Another possible limitation may be that some siblings of schizophrenia patients could have used a defensive method of answering. Although difficult to measure objectively, it has been hypothesized that questionnaires with overt psychotic-like contents are more vulnerable to a defensive response style in the relatives of schizophrenia patients (37). Both CAPE positive and negative symptom scores and SIS-R positive schizotypy scores did not differ between healthy siblings of 


\section{Lataster et al.}

patients compared with controls. As these symptoms were expected to be higher in siblings of schizophrenia patients because of familial vulnerability for psychotic symptoms, this suggests that defensive answering in some siblings could have lowered associations in healthy sib-pairs OAF.

Furthermore, given the symptomatic and genetic overlap between schizophrenia and bipolar disorder, including siblings OAF with a diagnosis of bipolar disorder $(N=5$ in the patient-relative sibpair analyses, and $N=1$ in the healthy sib-pairs OAF analyses) may have influenced the results on familial associations. However, repeating the analyses after excluding these participants did not change the results.

Finally, the sample was not balanced in terms of statistical power for the different comparisons, as the number of patient-relative sib-pairs was much higher than in the other two groups. Therefore, interpretation of results was driven by size of the associations, and not only on statistical significance.

\section{Acknowledgements}

We would like to thank the families who gave their time and effort to make this GROUP project possible. We are grateful to Dr. Marjan Drukker who has helped us with the conceptual design of the statistical analyses.

\section{Declaration of interest}

Professor De Haan has received research funding from Eli Lilly and honoraria from Eli Lilly, Janssen-Cilag, BMS and AstraZeneca. Professor van Os is/has been an unrestricted research grant holder with, or has received financial compensation as an independent symposium speaker from Eli Lilly, BMS, Lundbeck, Organon, Janssen-Cilag, GSK, AstraZeneca, Pfizer and Servier. Dr Cahn is/has been an unrestricted research grant holder with, or has received financial compensation as an independent symposium speaker or as a consultant from Eli Lilly, BMS, Lundbeck, Sanofi-Aventis, Janssen-Cilag, AstraZeneca and Schering-Plough. Professor Myin-Germeys has received financial compensation as an independent symposium speaker from BMS and Janssen-Cilag. Professor Kahn is/ has been an unrestricted research grant holder with, or has received financial compensation as an independent symposium speaker or as a consultant from AstraZeneca, Eli Lilly, Janssen-Cilag, Otsuka, Sinovion, Roche and Envivo. All other authors declare no conflict of interest.

\section{Financial disclosure}

The analyses were supported by unrestricted grants from Jansen-Cilag, Eli Lilly and Company, AstraZeneca and Lundbeck. The infrastructure for the GROUP study is funded by grant 10-000-1002 from the Geestkracht program of the Dutch Health Research Council and matching funds from participating universities and mental health care organizations in the Netherlands (Amsterdam: Academic Psychiatric Centre
AMC, Ingeest, Arkin, Dijk en Duin, Rivierduinen, Erasmus MC and GGZ Noord Holland Noord; Utrecht: University Medical Centre Utrecht, Altrecht, Symfora, Meerkanten, Riagg Amersfoort and Delta; Groningen: University Medical Center Groningen, Lentis, GGZ Friesland, GGZ Drenthe, Dimence, Mediant, GGZ De Grote Rivieren and Parnassia Bavo Groep; and Maastricht: Maastricht University Medical Center, GGZ Eindhoven, GGZ Midden-Brabant, GGZ Oost-Brabant, GGZ Noord-Midden Limburg, Mondriaan Zorggroep, Prins Clauscentrum Sittard, RIAGG Roermond, Universitair Centrum Sint-Jozef Kortenberg, CAPRI University of Antwerp, PC Ziekeren Sint-Truiden, PZ Sancta Maria Sint-Truiden, GGZ Overpelt and OPZ Rekem). The research leading to these results has received funding from the European Community's Seventh Framework Program under grant agreement HEALTH-F2-2009-241909 (project EU-GEI).

\section{References}

1. Kendler KS, McGuire M, Gruenberg AM, O'HARE A, Spellman M, Walsh D. The Roscommon Family Study. I. Methods, diagnosis of probands, and risk of schizophrenia in relatives. Arch Gen Psychiatry 1993;50:527-540.

2. Kendler KS, McGuire M, Gruenberg AM, O'HARE A, Spellman M, Walsh D. The Roscommon Family Study. III. Schizophrenia-related personality disorders in relatives. Arch Gen Psychiatry 1993;50:781-788.

3. Kendler KS, Gardner CO. The risk for psychiatric disorders in relatives of schizophrenic and control probands: a comparison of three independent studies. Psychol Med 1997; 27:411-419.

4. Van Os J, Marcelis M, Sham P, Jones P, Gilvarry K, MurRAY R. Psychopathological syndromes and familial morbid risk of psychosis. Br J Psychiatry 1997;170:241-246.

5. Lataster T, Myin-Germeys I, Derom C, Thiery E, Van Os J. Evidence that self-reported psychotic experiences represent the transitory developmental expression of genetic liability to psychosis in the general population. Am J Med Genet B Neuropsychiatr Genet 2009;150B:1078-1084.

6. Fanous A, Gardner C, Walsh D, Kendler KS. Relationship between positive and negative symptoms of schizophrenia and schizotypal symptoms in nonpsychotic relatives. Arch Gen Psychiatry 2001;58:669-673.

7. Mata I, Gilvarry CM, Jones PB, Lewis SW, Murray RM, Sнам PC. Schizotypal personality traits in nonpsychotic relatives are associated with positive symptoms in psychotic probands. Schizophr Bull 2003;29:273-283.

8. Mata I, Sham PC, Gilvarry CM, Jones PB, Lewis SW, Murray RM. Childhood schizotypy and positive symptoms in schizophrenic patients predict schizotypy in relatives. Schizophr Res 2000;44:129-136.

9. Chen LS, Rice TK, Thompson PA, Barch DM, Csernansky JG. Familial aggregation of clinical and neurocognitive features in sibling pairs with and without schizophrenia. Schizophr Res 2009;111:159-166.

10. Lindenmayer JP, Bernstein-Hyman R, Grochowski S. Fivefactor model of schizophrenia. Initial validation. J Nerv Ment Dis 1994;182:631-638.

11. McGrath JA, Avramopoulos D, Lasseter VK et al. Familiality of novel factorial dimensions of schizophrenia. Arch Gen Psychiatry 2009;66:591-600.

12. Nuechterlein KH, Asarnow RF, Subotnik KL et al. The structure of schizotypy: relationships between neurocognitive and personality disorder features in relatives of schizophrenic patients in the UCLA Family Study. Schizophr Res 2002;54:121-130. 
13. Vollema MG, Van Den Bosch RJ. The multidimensionality of schizotypy. Schizophr Bull 1995;21:19-31.

14. Kwapil TR, Barrantes-Vidal N, Silvia PJ. The dimensional structure of the Wisconsin Schizotypy Scales: factor identification and construct validity. Schizophr Bull 2008;34:444-457.

15. Craver JC, Pogue-Geile MF. Familial liability to schizophrenia: a sibling study of negative symptoms. Schizophr Bull 1999;25:827-839.

16. Korver N, Quee PJ, Boos HB, Simons CJ, De Haan L. Genetic Risk and Outcome of Psychosis (GROUP), a multi site longitudinal cohort study focused on gene-environment interaction: objectives, sample characteristics, recruitment and assessment methods. Int $\mathbf{J}$ Methods Psychiatr Res 2012;21:205-221.

17. APA. Diagnostic and statistical manual of mental disorders, 4th edn, Text Revision. Washington, DC: American Psychiatric Association, 2000.

18. Andreasen N, Flaum M, Arndt S. The comprehensive assessment of symptoms and history (CASH). An instrument for assessing diagnosis and psychopathology. Arch Gen Psychiatry 1992;49:615-623.

19. Wing JK, Babor T, Brugha T et al. SCAN. Schedules for clinical assessment in neuropsychiatry. Arch Gen Psychiatry 1990;47:589-593.

20. Konings M, BaK M, Hanssen M, Van Os J, Krabbendam L. Validity and reliability of the CAPE: a self-report instrument for the measurement of psychotic experiences in the general population. Acta Psychiatr Scand 2006;114:55-61.

21. Stefanis NC, Hanssen M, Smirnis NK et al. Evidence that three dimensions of psychosis have a distribution in the general population. Psychol Med 2002;32:347-358.

22. Peters ER, Joseph SA, Garety PA. Measurement of delusional ideation in the normal population: introducing the PDI (Peters et al. Delusions Inventory). Schizophr Bull 1999;25:553-576.

23. Vollema MG, Ormel J. The reliability of the structured interview for schizotypy-revised. Schizophr Bull 2000;26:619-629.

24. G.R.O.U.P. Evidence that familial liability for psychosis is expressed as differential sensitivity to cannabis. Arch Gen Psychiatry 2010;68:138-147.

25. Statacorp. STATA Statistical Software: release 11.0. Texas, College Station: StataCorp LD, 2009.
26. Van Os J, Kenis G, Rutten BP. The environment and schizophrenia. Nature 2010;468:203-212.

27. Wigman JT, Van Winkel R, Ormel J, Verhulst FC, Van Os J, Vollebergh WA. Early trauma and familial risk in the development of the extended psychosis phenotype in adolescence. Acta Psychiatr Scand 2012;126:266-273.

28. Read J, Van Os J, Morrison AP, Ross CA. Childhood trauma, psychosis and schizophrenia: a literature review with theoretical and clinical implications. Acta Psychiatr Scand 2005;112:330-350.

29. Janssen I, Krabbendam L, BaK M et al. Childhood abuse as a risk factor for psychotic experiences. Acta Psychiatr Scand 2004; 109:38-45.

30. Henquet C, Murray R, Linszen D, Van Os J. The environment and schizophrenia: the role of cannabis use. Schizophr Bull 2005;31:608-612.

31. Dragt S, Nieman DH, Schultze-Lutter F et al. Cannabis use and age at onset of symptoms in subjects at clinical high risk for psychosis. Acta Psychiatr Scand 2012;125: 45-53.

32. Rutten BP, Mill J. Epigenetic mediation of environmental influences in major psychotic disorders. Schizophr Bull 2009;35:1045-1056.

33. Xu B, Roos JL, Dexheimer P et al. Exome sequencing supports a de novo mutational paradigm for schizophrenia. Nat Genet 2011;43:864-868.

34. Girard SL, Gauthier J, Noreau A et al. Increased exonic de novo mutation rate in individuals with schizophrenia. Nat Genet 2011;43:860-863.

35. Glatt SJ, Stone WS, Nossova N, Liew N, Seidman LJ, TsuANG C-C. Similarities and differences in peripheral blood gene-expression signatures of individuals with schizophrenia and their first-degree biological relatives. Am J Med Genet B Neuropsychiatr Genet 2011;156B:869-887.

36. Kendler KS, Karkowski-Shuman L, O’Neill FA, Straub RE, Maclean CJ, Walsh D. Resemblance of psychotic symptoms and syndromes in affected sibling pairs from the Irish Study of high-density schizophrenia families: evidence for possible etiologic heterogeneity. Am J Psychiatry 1997;154:191-198.

37. Appels MCM, Sitskoorn MM, Vollema MG, Kahn RS. Elevated levels of schizotypal features in parents of patients with a family history of schizophrenia spectrum disorders. Schizophr Bull 2004;30:781-790. 